Pesq. Vet. Bras. 35(7):649-651, julho 2015

DOI: $10.1590 /$ S0100-736X2015000700008

\title{
Efeito anticoccidiano de extrato hidroalcoólico de Artemisia annua em camas de aves contaminadas com Eimeria sp. ${ }^{1}$
}

\author{
Lew Kan Sprenger ${ }^{2 *}$, Luciano Henrique Campestrini ${ }^{3}$, Fábio Tomio Yamassaki ${ }^{3}$, \\ Andréia Buzatti ${ }^{2}$, Juliana Bello Baron Maurer ${ }^{3}$, Selma Faria Zawadzki Baggio ${ }^{3}$, \\ Pedro Melillo de Magalhães ${ }^{4}$ e Marcelo Beltrão Molento ${ }^{2,5}$
}

\begin{abstract}
Sprenger L.K., Campestrini L.H., Yamassaki F.T., Maurer J.B.B., Baggio S.F.Z., Magalhães P.M. \& Molento M.B. 2015. [Anticoccidial effect of Artemisia annua hydroalcoholic extract in poultry beds contaminated with Eimeria sp.] Efeito anticoccidiano de extrato hidroalcoólico de Artemisia annua em camas de aves contaminadas com Eimeria sp. Pesquisa Veterinária Brasileira 35(7):649-651. Departamento de Medicina Veterinária, Universidade Federal do Paraná, Rua dos Funcionários 1540, Juvevê, Curitiba, PR 80035050, Brazil. E-mail: lew.sprenger@gmail.com

The aim of this study was to determine the efficacy of hydroalcoholic extract of Artemisia annua against oocysts of Eimeria sp. in contaminated poultry beds. The extract was produced after 7 days of storage at $4^{\circ} \mathrm{C}$, which was used to perform the phytochemical screening; the artemisinin measurement; the total phenolic; antioxidant testing and toxicity test. To test the anticoccidial activity, the birds space composed of shaver trees, were contaminated with 5000 oocysts. Four treatment were formed, in triplicate, were used in different concentrations as G1: $12 \mathrm{mg} / \mathrm{mL}, \mathrm{G} 2:=9 \mathrm{mg} / \mathrm{mL}, \mathrm{G} 3: 6 \mathrm{mg} / \mathrm{mL}$, and C-: water. After contamination $800 \mathrm{~mL}$ of the herbal at different concentrations were sprayed on the bed and collected, in triplicate, $10 \mathrm{~cm}^{2}$ each site, randomly, at times: 0, 3, 6, 24, 48, and 72 hours after application. In phytochemical analysis, were shown compounds with antiparasitic properties, such as flavonoids and tannins. The herbal contained $59.409 \pm 1.47 \mathrm{mg} / \mathrm{dL}$ artemisinin. The product at a concentration of $12 \mathrm{mg}$. $\mathrm{mL}^{-1}$ showed efficacy from 44.25 to $40.71 \%$. The results of biochemical tests, with the in vitro test showed that the extract has produced high potential for combating Eimeria sp.
\end{abstract}

INDEX TERMS: Coccidiosis, Artemisia annua, phytotherapy, alternative methods.

RESUMO.- 0 objetivo deste estudo foi avaliar a eficácia do extrato hidroalcoólico de Artemisia annua frente a oocistos de Eimeria sp. em camas contaminadas. 0 extrato foi produzido com 7 dias de percolação a $4^{\circ} \mathrm{C}$, sendo posteriormente realizada a marcha fitoquímica; dosagem de fenóis totais, quantificação de artemisinina, ensaio antio-

\footnotetext{
${ }^{1}$ Recebido em 16 de janeiro de 2015.

Aceito para publicação em 30 de abril de 2015.

${ }^{2}$ Departamento de Medicina Veterinária, Universidade Federal do Paraná (UFPR), Rua dos Funcionários 1540, Juvevê, Curitiba, PR 80035-050, Brasil. *Autor para correspondência: lew.sprenger@gmail.com

${ }^{3}$ Departamento de Bioquímica, UFPR, Avenida Coronel Francisco Heráclito dos Santos 210, Jardim das Américas, Curitiba, PR 81531-970.

${ }^{4}$ Centro Pluridisciplinar de Pesquisas Químicas, Biológicas e Agrícolas, Rua Alexandre Cazelatto 999, Vila Betel, Paulínia, SP 13081-970, Brasil.

${ }^{5}$ Instituto Nacional de Ciência e Tecnologia - Pecuária (INCT-Pecuária), Avenida Antonio Carlos 6627, Belo Horizonte, MG 31270-90, Brasil.
}

xidante e teste de toxicidade. Para testar a atividade anticoccidiana, camas de aves compostas de cepilho de árvores foram contaminadas com 5000 oocistos. Foram formados quatro tratamentos, em triplicata, nos quais foram usadas diferentes concentrações, sendo G1: 12mg/mL, G2: 8mg/ $\mathrm{mL}$, G3: $4 \mathrm{mg} / \mathrm{mL}$ e C-: água. Após a contaminação, foram aspergidos, $800 \mathrm{~mL}$ dos extratos nas diferentes concentrações sobre as camas e coletadas, em triplicatas, $10 \mathrm{~cm}^{2}$ de cada local, aleatoriamente, nos tempos: $0,3,6,24,48$, e 72 horas após a aplicação. Nas análises fitoquímicas, foram evidenciados diversos compostos com propriedades antiparasitárias, como flavonoides e taninos. 0 fitoterápico continha $59,409 \pm 1,47 \mu \mathrm{g} / \mathrm{dL}$ de artemisinina. 0 produto na concentração de $12 \mathrm{mg} \cdot \mathrm{mL}^{-1}$ apresentou eficácia entre 45,5 e $42,1 \%$. Os resultados dos testes bioquímicos, juntamente com os encontrados no teste anticoccidiano, evidenciaram que o extrato produzido possui alto potencial para combater Eimeria sp. 
TERMOS DE INDEXAÇÃO: Coccidiose, Artemisia annua, fitoterapia, métodos alternativos.

\section{INTRODUÇÃO}

A coccidiose, doença causada por protozoários do gênero Eimeria, causa graves prejuízos econômicos, devido a episódios de diarreia e mortes em animais jovens.

A forma usual de controle da coccidiose em frangos comerciais é feito com o uso preventivo de compostos químicos e de forma intensiva, com rápida troca de produtos. Este uso indiscriminado acarreta na seleção de organismos resistentes e com isso, a população resistente ao princípio ativo não é danificada e passa os seus genes de resistência para as futuras gerações (Molento 2005). Este é, destacadamente, um dos problemas mais sérios enfrentados não só na avicultura comercial, mas nas demais cadeias produtivas de proteína de origem animal.

Devido a estes problemas ocasionados pelo uso inadequado dos anti-helmínticos, diversos trabalhos estão sendo realizados buscando resolver essa situação, sendo que o uso de produtos fitoterápicos tem demonstrando resultados promissores. Artemisia annua se destaca como uma das potenciais soluções para auxiliar no controle parasitário dos animais de produção (Hasheminia et al. 2011).

O objetivo do estudo foi avaliar o efeito da utilização do extrato hidroalcoólico de $A$. annua no local de permanência de aves, composto por cepilho de árvore raspado contaminados com oocistos de Eimeria sp.

\section{MATERIAL E MÉTODOS}

Material vegetal. Artemisia annua utilizada no estudo foi plantada no Centro Pluridisciplinar de Pesquisas Químicas, Biológicas e Agrícolas (CPQBA) da Universidade de Campinas (Unicamp). A espécie está depositada no herbário do local, sob o número 979.

Produção do extrato. Para a produção do extrato hidroalcoólico de sete dias (H.7), utilizou-se um frasco de cor âmbar, no qual foram colocadas $64 \mathrm{~g}$ de folhas junto com $640 \mathrm{~mL}$ de álcool $80 \%(\mathrm{v} / \mathrm{v})$, o qual ficou armazenado em refrigerador a $4^{\circ} \mathrm{C}$ por uma semana.

Análises fitoquímicas. Posteriormente se realizou a marcha fitoquímica qualitativa descrita por Matos 1998, buscando verificar a presença de metabólitos secundários (fenóis, taninos, antocianinas, antocianidinas, leucoantocianidinas, esteróides, triterpenos, saponinas, resinas e alcalóides). A dosagem de artemisinina foi realizada no laboratório de fitoquímica do CPQBA-Unicamp, pelo método de cromatografia líquida de alta eficiência (CLAE), seguindo a metodologia descrita por Celeghini et al. (2009). A atividade toxicidade do extrato foi avaliada através do teste de letalidade frente a Artemia salina Leach, seguindo a metodologia de Meyer et al. (1982).

Amostragem. Durante o mês de março de 2013, o teste foi realizado na Fazenda Experimental do Canguiri, do Setor de Ciências Agrárias da Universidade Federal do Paraná, UFPR, localizada no município de Pinhais. Doze boxes contendo camas compostas por cepilho foram contaminadas com no mínimo 5000 oocistos de Eimeria sp. cada. Os boxes eram separados por uma parede de tijolos. Foram formados quatro tratamentos, contendo três boxes em cada, nos quais foram usadas diferentes concentrações do H.7, sendo G1: 12mg/mL, G2: $8 \mathrm{mg} / \mathrm{mL}$, G3: 4mg/mL e C-: água.
Análise da eficácia. Com o auxílio de um quadrado de madeira com $10 \mathrm{~cm}^{2}$, foram coletadas amostras de cada cama, de maneira aleatória, nos tempos: 0, 3, 6, 24, 48 e 72h após a aplicação dos extratos. Cada amostra repousou por 15 minutos em Becker, com capacidade de $1 \mathrm{~L}$, contendo o material retirado, água destilada e duas gotas de detergente neutro. 0 material foi lavado de maneira consecutiva em peneiras de 250,150, 75 e 20 $\mu$ m. Após esta sequência de lavagem com água destilada, o conteúdo da última peneira foi coletado e distribuído para tubos de $50 \mathrm{~mL}$ para serem centrifugados. Novamente o material foi centrifugado nas mesmas condições que a anterior e então se colocou uma lâmina de vidro sobre o tubo. Após 15 minutos a lâmina foi retirada e a contagem de oocistos foi realizada em microscópio eletrônico em aumento de $10 \mathrm{x}$.

Análise estatística. Os dados foram comparados por análise de variância pelo teste ANOVA, seguido do teste de Tukey. Todas as análises foram realizadas usando o programa GraphPad Prism 5.

\section{RESULTADOS}

Foram encontrados os seguintes metabólitos; alcaloides, catequinas, esteróides, fenóis, resinas, taninos e triterpenos. Antocianinas, antocianidinas e leucoantocianidinas não foram detectadas. A dosagem de artemisinina em CLAE indicou a concentração de $59,409 \pm 1,472 \mu \mathrm{g} / \mathrm{dL}$. 0 teste de toxicidade apresentou $\mathrm{DL}_{50}$ de $3,827 \mu \mathrm{g} / \mathrm{mL}\left(\mathrm{R}^{2}=0,9478\right)$.

Já os resultados da diminuição do número de oocistos de Eimeria sp. após o intervalo de tempo "T" de aplicação do extrato H.7 está disposto no Quadro 1 e mostraram um efeito dose-dependente. Os melhores valores de eficácia foram encontrados com a utilização do extrato na concentração de $12 \mathrm{mg} \cdot \mathrm{ml}^{-1}$, variando de 44,25 a 40,71\%.

Quadro 1. Número médio de oocistos de Eimeria sp., desvio padrão ( \pm ) e eficácia (\%) no intervalo de tempo "T" após a aplicação do extrato hidroalcoólico de 7 dias, obtido a partir de Artemisia annua

\begin{tabular}{ccccc}
\hline Horas $(\mathrm{T})$ & $\mathrm{C}^{\mathrm{a}}$ & $\mathrm{G}^{\mathrm{b}}$ & $\mathrm{G}^{\mathrm{c}}$ & $\mathrm{G}^{\mathrm{d}}$ \\
\hline \multirow{2}{*}{0} & $108 \pm 7$ & $104,7 \pm 4,6$ & $114,3 \pm 6$ & $99,7 \pm 6,5$ \\
& $(0 \%) \mathrm{Aa}$ & $(0 \%) \mathrm{Ab}$ & $(0 \%) \mathrm{Ab}$ & $(0 \%) \mathrm{Ab}$ \\
3 & $103,3 \pm 6,3$ & $85,3 \pm 3,5$ & $82,3 \pm 6,7$ & $54,7 \pm 5,5$ \\
& $(4,3 \%) \mathrm{Da}$ & $(18,5 \%) \mathrm{Ca}$ & $(28 \%) \mathrm{Ba}$ & $(45,2 \%) \mathrm{Aa}$ \\
6 & $101,6 \pm 4,1$ & $84,3 \pm 5,9$ & $81,7 \pm 8,1$ & $54,3 \pm 6,1$ \\
& $(5,9 \%) \mathrm{Da}$ & $(19,4 \%) \mathrm{Ca}$ & $(28,6 \%) \mathrm{Ba}$ & $(45,5 \%) \mathrm{Aa}$ \\
24 & $99,3 \pm 9,3$ & $85 \pm 2,4$ & $82 \pm 4,51$ & $57,7 \pm 5,7$ \\
& $(8,1 \%) \mathrm{Da}$ & $(18,8 \%) \mathrm{Ca}$ & $(28,3 \%) \mathrm{Ba}$ & $(42,1 \%) \mathrm{Aa}$ \\
48 & $99,3 \pm 4,6$ & $89 \pm 1,5$ & $83 \pm 2,1$ & $56,7 \pm 5,8$ \\
& $(8,1 \%) \mathrm{Da}$ & $(15 \%) \mathrm{Ca}$ & $(27,4 \%) \mathrm{Ba}$ & $(43,1 \%) \mathrm{Aa}$ \\
72 & $102,7 \pm 2,1$ & $86 \pm 7$ & $86 \pm 7$ & $54,7 \pm 1,5$ \\
& $(4,9 \%) \mathrm{Da}$ & $(17,8 \%) \mathrm{Ba}$ & $(24,8 \%) \mathrm{Ba}$ & $(45,2) \mathrm{Aa}$
\end{tabular}

${ }^{\mathrm{a}} \mathrm{C}=$ Água (controle negativo), ${ }^{\mathrm{b}} \mathrm{G} 1=12 \mathrm{mg} / \mathrm{mL},{ }^{\mathrm{c}} \mathrm{G} 2=9 \mathrm{mg} / \mathrm{mL},{ }^{\mathrm{d}} \mathrm{G} 3=$ $6 \mathrm{mg} / \mathrm{mL}$. Letras maiúsculas comparam as eficácias nas mesmas linhas e letras minúsculas nas colunas; letras diferentes indicam diferença estatística significativa $(\mathrm{P}<0,05)$.

\section{DISCUSSÃO}

Manter o ambiente com uma carga de Eimeria sp. baixa é recomendável, pois faz com que o animal entre em contato com o parasita e assim estimula o sistema imune a desenvolver uma resposta frente ao agente. Ao mesmo faz com que essa infecção seja controlada, não provocando graves lesões e assim não interferindo no estado geral do animal (Oliveira et al. 2011). 
A resistência aos anticoccidianos é um problema antigo na avicultura. A eficácia do extratos no presente experimento ficou abaixo de $45 \%$. Contudo, o resultado teve ação dose-dependente. Os oocistos são classificados como agentes etiológicos mais resistentes à destruição, após os príons, sendo sua eliminação do ambiente difícil devido a sua alta resistência à destruição.

Remmal et al. 2011, incubaram oocistos de Eimeria sp. com Artemisia annua, com o objetivo de destruir-los. Os dados in vitro demonstraram que a máxima destruição ocorreu após $6 \mathrm{~h}$ de contato entre o protozoário e os fitoterápicos. Nesse experimento, apesar de ter sido utilizada uma boa quantidade de fitoterápico nas camas não se pode garantir que elas tenham ficado impregnadas com a solução contendo os extratos.

Allen et al. 1997, relataram efeitos preventivos da planta contra Eimeria tenella e E. acervulina, com o fornecimento de folhas secas de A. annua. Segundo Brisibe et al. 2009, além do combate a coccidiose, a suplementação com $20 \%$ de folhas secas nas dietas das aves melhorou o ganho de peso e a qualidade da gema dos ovos.

Os resultados obtidos na marcha fitoquímica corroboram com os encontrados na literatura (Brisibe et al. 2009). Alguns compostos que possuem comprovado efeito antiparasitário, como os taninos e artemisinina. Os taninos reduzem o metabolismo do parasita, por se ligar aos nutrientes e indisponilizá-los. A artemisinina é o principal responsável pela ação anti-helmíntica dos extratos produzidos com A. апnиa (Sprenger et al. 2015). Este composto interfere nas proteínas de transporte na mitocôndria do parasita e modula a função imune do hospedeiro. Para coccidiose, acredita-se que ocorra uma interferência no sistema reprodutivo, fazendo com que novas proles não sejam formadas. Outro mecanismo ocorre pela redução na capacidade dos oocistos esporular ou sobreviver no ambiente, devido a alterações no metabolismo (Almeida et al. 2012).

O ensaio de letalidade frente ao microcrustáceo Artemia salina, por possuir alta confiabilidade para testar o efeito tóxico de fitoterápicos com propriedades antiparasitárias (Meyer et al. 1982). Todavia, extratos com baixa toxicidade possuem propriedades desejáveis para utilização no controle de parasitas no ambiente (Meyer et al. 1982). Os resíduos de antiparasitários no meio ambiente são de grande preocupação, pois muitos deles não são degradáveis e ficam por muito tempo no ambiente contaminado.

\section{CONCLUSÕES}

Quanto aos tratamentos aplicados e analisando a dimensão do problema causado por Eimeria sp., conclui-se que o extrato hidroalcoólico de Artemisia annua de 7 apresentou um efeito satisfatório, demonstrando uma clara ação dose-dependente.

Novos estudos necessitam ser realizados, para elucidar as reais propriedades destes fitoterápicos.

\section{REFERÊNCIAS}

Allen P.C., Lydon J. \& Danforth H.D. 1997. Effects of components of $\mathrm{Ar}$ temisia annua on coccidia infections in chickens. Poult. Sci. 76:11561163.

Almeida G.F., Horsted K., Thamsborg S.M., Kyvsgaard N.C., Ferreira J.F.S. \& Hermansen J.E. 2012. Use of Artemisia annua as a natural coccidiostat in free-range broilers and its effects on infection dynamics and performance. Vet. Parasitol. 186:178-187.

Brisibe E.A., Umoren U.E., Brisibe F., Magalhäes P.M., Ferreira J.F., Luthria D., Wu X. \& Prior R.L. 2009. Nutritional characterisation and antioxidant capacity of different tissues of Artemisia annua L. Food Chemistry 115(4):1240-1246.

Celeghini R.M.S., Sousa I.M.O., Silva A.P., Rodrigues R.A.F. \& Foglio M.A. 2009. Development and validation of analytical methodology by HPLCIR for evaluation of artemisinin on Artemisa annua L. Química Nova 32(4):875-878.

Hasheminia S.M., Sendi J.J., Jahromi K.T. \& Moharramipour S. 2011. The effects of Artemisia annua L. and Achillea millefolium L. crude leaf extracts on the toxicity, development, feeding efficiency and chemical activities of small cabbage Pieris rapae L. (Lepidoptera: Pieridae). Pestic. Biochem. Physiol. 99:244-249

Matos F.J.A. 1998. Introdução à Fitoquímica Experimental. 2ª ed. EUFC, Fortaleza. 237p.

Meyer B.N., Ferrigni N.R., Putnam J.E., Jacobsen L.B., Nichols D.E. \& McLaughlin J.L. 1982. Brine shrimp: a convenient general bioassay for active plant constituents. Planta Medica 45(5):31-34.

Molento M.B. 2005. Resistência parasitária em helmintos de eqüídeos e propostas de manejo. Ciência Rural 35(6):1469-1477.

Oliveira U.C., Fraga J.S., Licois D., Pakandl M. \& Gruber A. 2011. Development of molecular assays for the identification of the 11 Eimeria species of the domestic rabbit (Oryctolagus cuniculus). Vet. Parasitol. 176(23):275-280

Remmal A., Achahbar S., Bouddine L., Chami N. \& Chami F. 2011. In vitro destruction of Eimeria oocysts by essential oils. Vet. Parasitol. 182:121126.

Sprenger L.K., Buzatti A., Campestrini L.H., Yamassaki F.T., Maurer J.B.B., Baggio S.F.Z., Magalhães P.M. \& Molento M.B. 2015. Ovicidal and larvicidal activity of Artemisia annua hydroalcoholic extract against gastrointestinal parasites in cattle. Arq. Bras. Med. Vet. Zootec. 67(1):25-31. 